\title{
SLICC-based Phenotype of Juvenile Systemic Lupus Erythematosus in the Philippines
}

\author{
Cherica A. Tee ${ }^{1}$ and Michael L. Tee ${ }^{2}$ \\ ${ }^{1}$ Department of Pediatrics, College of Medicine and Philippine General Hospital, University of the Philippines Manila \\ ${ }^{2}$ Department of Physiology, College of Medicine, University of the Philippines Manila
}

\begin{abstract}
Objective. To describe the clinical profile of Filipino pediatric SLE patients as determined using the 2012 Systemic Lupus International Collaborating Clinics (SLICC) classification criteria.

Methods. We checked which among the SLICC criteria were fulfilled by Filipino pediatric SLE patients when we examined them and their case records, as part of a nationwide genetic study on SLE conducted from October 2015 to March 2017.
\end{abstract}

Results. Ninety-seven (out of 321) who were diagnosed to have SLE before 19 years of age were evaluated. The mean age of the population at the time of evaluation was $19.8 \pm 6.9$ years. Females comprised $94 \%$ of our population. Mean age of onset was $14.4 \pm 2.7$ years, while the mean age of diagnosis was at $14.5 \pm 2.6$ years. Acute cutaneous rash was found in $87 \%$; oral ulcers 65\%; renal disorder 63\%; non-scarring alopecia 61\%; arthritis $58 \%$; chronic cutaneous rash $36 \%$; leukopenia $35 \%$; hemolytic anemia $34 \%$; serositis $25 \%$; thrombocytopenia $23 \%$, and neurologic disorder 8\%. Anti-nuclear antibody was present in 85\%; low complement 32\%; anti-dsDNA 28\%; direct Coombs' $16 \%$; antiphospholipid antibody $3 \%$; and anti-Smith antibody $1 \%$. Kidney biopsy was performed in only $14 \%$ (14/97) of patients, of whom $27 \%$ had class III histopathologic characteristic.

Conclusions. Filipino pediatric SLE patients typically present with mucocutaneous, renal, and musculoskeletal involvement. Cardiopulmonary and neurologic manifestations are found to be less common among them. Finally, renal biopsy is not commonly performed among these patients.

Key Words: Systemic lupus erythematosus; children; Philippines; SLICC

\section{INTRODUCTION}

Poster presented at the $19^{\text {th }}$ Asia Pacific League of Associations for Rheumatology Congress and $3^{\text {rd }}$ Annual Conference of the Emirates Society for Rheumatology, October 19, 2017, Dubai, UAE

Corresponding author: Cherica A. Tee, MD, MBA

Department of Pediatrics

Philippine General Hospital

University of the Philippines Manila

Taft Ave., Ermita, Manila 1000, Philippines

Email: catee@up.edu.ph
Systemic lupus erythematosus (SLE) is a complex prototypic autoimmune disease commonly affecting women at their child-bearing age at a prevalence of 20 to 150 per 100,000. In Asia, prevalence data generally fall within 30-50 per 100,000 population $^{1}$, a rate higher than the $25 / 100,000$ reported in $\mathrm{UK}^{2}$. Twenty percent of SLE patients have disease onset during childhood and adolescence. It has a global incidence of $0.36-2.5$ per 100,000 and prevalence rate of 1.89 to 25.7 per 100,000 children. ${ }^{3}$ This report describes the clinical and immunologic profile of childhood-onset SLE patients enrolled in the first nationwide SLE Genetics Study in the Philippines using the 2012 Systemic Lupus International Collaborating Clinics (SLICC) criteria.

\section{PATIENTS AND METHODS}

This report is part of the research program of the UP Manila Genetics of SLE Study Group done during the 
period of October 2015 to March 2017. All procedures have been reviewed and approved in compliance with the ethical standards of the National Institutes of Health, University of the Philippines Manila-Research Ethics Board and the World Medical Association Declaration of Helsinki on ethical principles for medical research involving human subjects. All participants signed the informed consent and/ or assent forms.

We recruited volunteer participants diagnosed with SLE who satisfy the 2012 SLICC classification criteria from rheumatology clinics in both private and government institutions, including the Philippine General Hospital, University of the Philippines Manila, communities in Metro Manila, Baguio, Nueva Ecija, Batangas, Cebu, and Iloilo. Trained research staff gathered relevant demographic and health information by interview using the standardized forms. Available medical records were reviewed as crossreference for the diagnosis of SLE. We excluded patients with co-existing autoimmune diseases like rheumatoid arthritis, juvenile idiopathic arthritis, systemic vasculitides, dermatomyositis, scleroderma, mixed connective tissue disease, and overlap syndromes. We also obtained relevant laboratory information from the subject's medical record. No new diagnostic procedures were performed. Patients who were diagnosed to have SLE prior to their $19^{\text {th }}$ birthday were evaluated.

\section{RESULTS}

There were ninety-seven patients with juvenile SLE (jSLE) out of the 321 recruited in the Genetics of SLE Study. There were 91 females and 6 males at 15:1 ratio. The mean age of onset of symptoms was $14.4 \pm 2.7$ years (range, 7-18 years) and the mean age of SLE diagnosis was $14.5 \pm 2.6$ years (range, $7-18$ years).

The frequency of the different clinical and immunologic manifestations based on the SLICC criteria is shown on Table 1. The common clinical manifestations of jSLE were acute cutaneous rash (87\%), oral ulcers $(65 \%)$, renal disorder (63\%), non-scarring alopecia (61\%), and arthritis (58\%). Hematologic manifestations of hemolytic anemia, leukopenia, and thrombocytopenia were found in 34\%, 35\%, and $23 \%$ of patients, respectively. Serositis was present in $25 \%$ and neurologic disorder in $8 \%$. While not all immunologic tests were done on all participants, antinuclear antibody was found in the majority at $88 \%$. Low complement level was seen in $33 \%$, positive anti-dsDNA in $29 \%$, direct Coombs' test in $16 \%$, antiphospholipid antibody in $3 \%$, and anti-Smith antibody in $1 \%$ of the patients. Kidney biopsy was performed in only $14 \%$ of patients, of whom $29 \%$ had focal proliferative glomerulonephritis (WHO Class III), followed by $21 \%$ each of mesangioproliferative (Class II), and diffuse proliferative glomerulonephritis (Class IV) and membranous nephropathy (Class V) in 7\%. No report was seen on the other $21 \%$ of patients.
Table 1. Demographic profile and SLE manifestations based on SLICC criteria

\begin{tabular}{|c|c|}
\hline Variable & $\begin{array}{c}\text { SLE } \\
N=97\end{array}$ \\
\hline Age (years, mean \pm SD) & $19.8 \pm 6.9$ \\
\hline Age at symptom onset (years, mean \pm SD) & $14.4 \pm 2.7$ \\
\hline Age at diagnosis (years, mean \pm SD) & $14.5 \pm 2.6$ \\
\hline Female sex, frequency (\%) & $91(94 \%)$ \\
\hline $\begin{array}{l}\text { SLE manifestations, frequency (\%) } \\
\text { Acute cutaneous lupus } \\
\text { Chronic cutaneous lupus } \\
\text { Oral or nasal ulcers } \\
\text { Non-scarring alopecia } \\
\text { Arthritis } \\
\text { Serositis } \\
\text { Renal } \\
\text { Neurologic } \\
\text { Leukopenia } \\
\text { Hemolytic anemia } \\
\text { Thrombocytopenia } \\
\end{array}$ & $\begin{array}{c}84(88 \%) \\
35(36 \%) \\
63(65 \%) \\
59(61 \%) \\
56(58 \%) \\
24(25 \%) \\
61(63 \%) \\
8(8 \%) \\
34(35 \%) \\
33(34 \%) \\
22(23 \%)\end{array}$ \\
\hline $\begin{array}{l}\text { SLE laboratory manifestations, frequency (\%) } \\
\text { ANA } \\
\text { Anti-dsDNA } \\
\text { Low complement } \\
\text { Kidney biopsy } \\
\text { Direct Coombs' test } \\
\text { Anti-Sm } \\
\text { Antiphospholipid antibody }\end{array}$ & $\begin{array}{c}85(88 \%) \\
28(29 \%) \\
32(33 \%) \\
14(14 \%) \\
16(16 \%) \\
1(1 \%) \\
3(3 \%)\end{array}$ \\
\hline
\end{tabular}

Note: SLICC - Systemic Lupus International Collaborating Clinics

\section{DISCUSSION}

In this first multi-center and multi-regional report in the Philippines, we used the 2012 SLICC SLE classification criteria in describing the main clinical and laboratory manifestations of juvenile SLE. The SLICC criteria was found to be more sensitive ( $99.9 \%$ vs. $84.3 \%$ ) but less specific ( $82.0 \%$ vs. $94.1 \%)$ than the ACR criteria. ${ }^{4}$ In a local validation study among juvenile SLE patients, the sensitivity was $94.0 \%$ (95\%CI 88.9-97.2) and the specificity was $96.7 \%$ (95\%CI 92.4-98.9). ${ }^{5}$ The higher specificity of the SLICC criteria leads to fewer misclassifications, making it better criteria for observational and clinical trial studies. ${ }^{6,7}$ In considering our results, we cited international studies as seen in Table 2. However, these cited papers used the revised 1997 ACR criteria $^{8-18}$ or the modified American Rheumatism Association criteria for $\mathrm{SLE}^{10,19}$. Only our study used the SLICC criteria. We included representative studies from the different regions of the world. Southeast Asia is represented by the countries Malaysia ${ }^{9}$, Singapore ${ }^{10}$, Vietnam ${ }^{11}$, and another local study from the Philippines ${ }^{8}$. Bangladesh ${ }^{12}$ and India ${ }^{19}$ represented South Asia, China ${ }^{13}$ of the East Asia and Iran ${ }^{14}$ of the Middle East. Other populations are from the continent of Australia ${ }^{15}$ through its Australian Paediatric Surveillance Unit, nine countries from Latin America ${ }^{16}$ obtained from the GLADEL (Grupo Latino Americano de Estudio del Lupus) database, Canada ${ }^{17}$ and four countries from Europe ${ }^{18}$ which were composed of $80 \%$ Caucasians. 
Table 2. Comparison of the main clinical and laboratory features of jSLE patients from our study and other international studies

\begin{tabular}{|c|c|c|c|c|c|c|c|c|c|c|c|c|c|}
\hline . & $\begin{array}{l}\text { Our study } \\
2019\end{array}$ & $\begin{array}{l}{ }^{2} \text { Gulay } \\
2011\end{array}$ & $\begin{array}{l}\text { allias }^{8} \\
2017\end{array}$ & $\begin{array}{l}\text { Tan9 } \\
2015\end{array}$ & $\begin{array}{l}\text { Dung }^{10} \\
2012\end{array}$ & $\begin{array}{l}{ }^{\text {aRahmanan }}{ }^{11} \\
2014\end{array}$ & 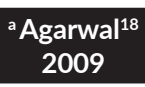 & $\begin{array}{l}{ }^{\circ}{ }^{\circ} \text { Feng'12 } \\
2013\end{array}$ & $\begin{array}{l}{ }^{2} \text { Fatemi'is } \\
2016 \\
{ }^{2}\end{array}$ &  & $\begin{array}{l}\text { Ramirez Gomez } \\
2008\end{array}$ & $\begin{array}{l}\text { Hiraki16 } \\
2008\end{array}$ & $\begin{array}{l}\text { Hoffman }{ }^{1} \\
2009\end{array}$ \\
\hline Country & Philippines & Philippines & Malaysia & Singapore & Vietnam & Bangladesh & India & China & Iran & Australia & Latin Americab & Canada & Europe $^{c}$ \\
\hline Number & 97 & 78 & 51 & 64 & 45 & 70 & 70 & 259 & 180 & 30 & 230 & 256 & 56 \\
\hline Female:Male ratio & $15: 1$ & 10:1 & $10: 1$ & $5: 1$ & 4:1 & $7: 1$ & 6:1 & $16: 1$ & $3.3: 1$ & $4: 1$ & $9: 1$ & 4.7:1 & 5:1 \\
\hline Age at diagnosis (years, mean $\pm S D$ ) & $14.5 \pm 2.6$ & $14 \pm 2.7$ & $12^{\mathrm{d}}$ & 11.9 & $12.8 \pm 2.5$ & $11.6 \pm 2.6$ & 10.5 & NS & NS & $12.6^{\mathrm{d}}$ & 16.4 & $13.1 \pm 3.2$ & 15 \\
\hline Mucocutaneous (\%) & NS & 92.3 & NS & 62.5 & NS & NS & NS & 78 & NS & NS & NS & NS & NS \\
\hline Acute rash (\%) & 87 & 76.9 & 52 & 45.3 & 67 & 71 & 57.1 & NS & 49 & 47 & 70.4 & 66 & 69.6 \\
\hline Chronic rash (\%) & 36 & 35.8 & 18 & 15.6 & 13 & NS & NS & NS & NS & 10 & 12.6 & 43 & 13.2 \\
\hline Photosensitivity & NS & 73 & 20 & 15.6 & 53 & 59 & 51.4 & NS & NS & 31 & 53 & 20 & 44.6 \\
\hline Oral ulcers (\%) & 65 & 67.9 & 40 & 32.8 & 38 & 73 & NS & NS & 10 & 17 & 49.1 & 30 & 28.6 \\
\hline Alopecia (\%) & 61 & 52.5 & 24 & 42.2 & NS & 51 & 45.7 & NS & NS & NS & NS & 29 & 41.1 \\
\hline Musculoskeletal (\%) & 58 & 53.8 & 44 & 56.3 & 58 & 74 & 65.7 & 49.8 & 50.5 & 76 & 83 & 67 & 59.3 \\
\hline Serositis (\%) & 25 & 21.7 & 28 & 7.8 & 36 & 10 & 2.8 & 23.2 & 5 & 14 & 17.4 & 15 & 18.5 \\
\hline Renal (\%) & 63 & 71.7 & 60 & 50 & 82 & 66 & 77.1 & 53.2 & 72.8 & 27 & 49.1 & 55 & 62.5 \\
\hline Neurologic (\%) & 8 & 32 & 9 & 12.5 & 16 & 26 & 21.4 & 5.4 & 11.7 & 3 & 11.3 & 27 & 20.4 \\
\hline Hematologic (\%) & NS & 69.2 & 60 & NS & 78 & NS & NS & 68 & NS & 77 & NS & NS & NS \\
\hline Hemolytic anemia (\%) & 34 & 10.2 & NS & 28.1 & NS & 16 & 60 & 43 & 12.2 & 40 & 16.4 & 25 & 38.5 \\
\hline Leukopenia (\%) & 35 & 32 & 6.1 & 67.2 & NS & 10 & NS & 38.4 & 11.1 & 40 & 46.1 & 36 & 63.6 \\
\hline Lymphopenia (\%) & NS & 41 & NS & 90.6 & NS & NS & NS & NS & NS & 60 & 60.4 & NS & 67.9 \\
\hline Thrombocytopenia (\%) & 23 & 25.6 & 4.1 & 32.8 & NS & 17 & 24.2 & 28.9 & 15 & 17 & 25.2 & 31 & 31.5 \\
\hline$\overline{A N A}(\%)$ & 85 & 98.5 & 98 & 98.4 & 67 & 97 & NS & 95.7 & 97.2 & 100 & 96.9 & 100 & NS \\
\hline Anti-dsDNA (\%) & 28 & NS & 34.7 & 90.6 & 95 & 91 & 77.1 & 57.8 & 85.5 & 86.7 & 67 & 84 & NS \\
\hline Anti-Sm (\%) & 1 & NS & NS & 37.5 & NS & NS & NS & 30.7 & NS & 26.7 & 51.3 & 48 & 60.7 \\
\hline Antiphospholipid antibody (\%) & 3 & NS & NS & NS & NS & 9 & NS & NS & 2.2 & 33 & NS & 45 & 17.9 \\
\hline Low complement (\%) & 32 & 8.9 & 83.3 & NS & NS & 83 & 80 & NS & 11.1 & NS & NS & NS & NS \\
\hline Coombs' test (\%) & 16 & NS & 70.6 & NS & 12 & NS & 58.3 & NS & NS & NS & NS & 25 & NS \\
\hline Kidney Biopsy (\%) & 14 & 30.8 & 49 & 32.8 & 64 & 60 & 100 & NS & 13.9 & 36.7 & NS & 55 & NS \\
\hline
\end{tabular}

Kidney Biopsy (\%)

"At diagnosis: ${ }^{b i n}=$ Iuded Mexico, Brazil, Argentina, Colombia, Ve

As expected, girls are more frequently affected than
oys but our report had the highest ratio at 15:1 comparable boys but our report had the highest ratio at 15:1 comparable to the China ${ }^{13}$ cohort of $16: 1$. The female to male ratio in other countries ranged from 3 to $10: 1$. of diagnosis of $14.5 \pm 2.6$ years is well within the reported range except those from Vietnam, Bangladesh, Australia, and India which may be due to their cut-off age for jSLE of either below 15 or 16 years.

Mucoctaneous involvement is the most commonly affected system in our report similar to the local study of Gulay and Dans on jSLe patients in the biggest tertiary hospital in Mantila j Southeast Asinn countries, Chinz Latin Americs and Europe with acute cutaneous lupus or mar ash as the most common presentation. Oral ulers and alopecin more frequent than chronic cutaneous rash among Filipinos. Musculoskeletal involvement seen in our cohort of jSLE is similar with the other countries, but is more frequenty reported in Bangladesh, Latin America, and Australia.

Lupus nephritis is one the most severe clinical manifestation of SLE associated with higher morbidity and mortality. It is more frequently a presenting manifestation among pediatric rather than adult-onset SLE. ${ }^{20}$ In our comparative table, sixty to eighty percent of children with lupus are aftlicted in the countries of Vietnam, India, Iran, Philippines, Bangladesh, Malaysia, and those in the continent of Europe. While our cohort had focal lupus nephritis (WHO Class III) with the highest proportion at $29 \%$, diffuse proliferative lupus nephritis (WHO Class IV) whe who had kidney biopsy in other populations. The report of While he low

mmon in our study t about one-third, it is common to our neighboring Asia ies of Singapore, Vietnam, and Australia with more than three-fourths of their cohort involved.

Cardiopulmonary and neurologic disorders are infrequent in the pediatric age group as compared to other organ involvement. We report occurrence of serositis in a quarter of our jSLE patients. It is more frequent in Vietnam Neurologic involvement is our least frequent manifestation at $8 \%$
The frequency of ANA positivity in our study (85\%) is lower than the other studies (95-100\%); even lower is among the Vietnamese children at $6 \%$. While not all our patients had complete antibody profile, the more frequen immunologic test dsDNA levels.

The report is limited with the small sample size with data collected from the various private and public rheumatology clinics in the Philippines. Consequently, there may be selection bias in the patient participation. It is an accepted wet that we are confoned wich suvival bias as patients succumbed to serious complications of lupus flare.

\section{CONCLUSION}

Filipino pediatric SLE patients typically present with mucocutaneous, renal, and musculoskeletal involvement. Cardiopulmonary and neurolooic manifestations are found to be less common among them. Finally, renal biopsy is not commonly performed among these patients.

\section{Acknowledgments}

The authors are grateful to UP Manila Chancellor Carmencita D. Padilla for the support given to the conduct of this study. This research was undertaken as part of the UP Manila Genetics of SLE Study Group with Dr. Eva Maria C. Dela Paz, Executive Director of the National Institutes of Health. The authors would also like to thank Drs. Mayla Wahab, Angeline Therese Santiago, Lea Galia, Marjorie Liwanag, Sherbeth Rey, Christopher Ryan Caduan, Elza Ma Dejoras, Karn Chiseng, Shanida Cance Call Mangubat, and Merle Barba fort

\section{Statement of Authorship}

Both authors participated in data collection and analysis, and approved the final version submitted.

\section{Author Disclosure}

Both authors declared no conflicts of interest. 


\section{Funding Source}

Funding was provided by the Philippine Council for Health Research and Development (PCHRD), Department of Science and Technology (DOST), Republic of the Philippines.

\section{REFERENCES}

1. Osio-Salido E, Manapat-Reyes H. Epidemiology of systemic lupus erythematosus in Asia. Lupus. 2010 Oct; 19(12):1365-73.

2. Drug and Therapeutics Bulletin. Systemic lupus erythematosus - an update. Drug Ther Bull. 2011 Jul; 49(7):81-4.

3. Pineles D, Valente A, Warren B, Peterson MGE, Lehman TJA, Moorthy LN. Worldwide incidence and prevalence of pediatric onset systemic lupus erythematosus. Lupus. 2011 Oct; 20(11):1187-92.

4. Hartman EAR, van Royen-Kerkhof A, Jacobs JWG, Welsing PMJ, Fritsch-Stork RDE. Performance of the 2012 Systemic Lupus International Collaborating Clinics classification criteria versus the 1997 American College of Rheumatology classification criteria in adult and juvenile systemic lupus erythematosus. A systematic review and meta-analysis. Autoimmun Rev. 2018 Mar; 17(3):316-22.

5. Kimseng KJN, Dans LF, Tee CA. AB0988 Validation of the Systemic Lupus International Collaborating Clinics (SLICC) Classification Criteria in juvenile systemic lupus erythematosus. Ann Rheum Dis. 2015 Jun; 74(Suppl 2):1229.

6. Lythgoe H, Morgan T, Heaf E, Lloyd O, Al-Abadi E, Armon K, et al; on behalf of the UK JSLE Study Group. Evaluation of the ACR and SLICC classification criteria in juvenile-onset systemic lupus erythematosus: a longitudinal analysis. Lupus. 2017 Oct; 26(12):1285-90.

7. Sag E, Tartaglione A, Batu ED, Ravelli A, Khalil SMA, Marks $\mathrm{SD}$, et al. Performance of the new SLICC classification criteria in childhood systemic lupus erythematosus: a multicentre study. Clin Exp Rheumatol. 2014; 32: 440-444.

8. Gulay CB, Dans LF. Clinical presentations and outcomes of Filipino juvenile systemic lupus erythematosus. Pediatr Rheumatol Online J. 2011 Feb; 9:7.

9. Ilias MI, Ali JMA, Ismail NZAN, Rostenberghe HV, Rahman AA. Pediatric Systemic Lupus Erythematosus Manifestations and Outcomes in a Tertiary Hospital. Lupus Open Access. 2017; 2(1):123.
10. Tan JHT, Hoh SF, Win MTM, Chan YH, Das L, Arkachaisri T. Childhood-onset systemic lupus erythematosus in Singapore: clinical phenotypes, disease activity, damage, and autoantibody profiles. Lupus. 2015 Aug; 24(9):998-1005. doi:10.1177/0961203315584413.

11. Dung NTN, Loan HT, Nielsen S, Zak M, Petersen FK. Juvenile systemic lupus erythematosus onset patterns in Vietnamese children: a descriptive study of 45 children. Pediatr Rheumatol Online J. 2012 Nov; 10(1):38. doi: 10.1186/1546-0096-10-38.

12. Rahman SA, Islam MI, Talukder MK, Islam MM, Huque SS, Roy RR. Presentation of childhood systemic lupus erythematosus in a tertiary care hospital. Bangladesh J Child Health. 2014; 38(3):124-9.

13. Feng X, Zou Y, Pan W, Wang X, Wu M, Zhang M, et al. Associations of clinical features and prognosis with age at disease onset in patients with systemic lupus erythematosus. Lupus. 2014 Mar; 23(3):327-34.

14. Fatemi A, Matinfar M, Smiley A. Childhood versus adult-onset systemic lupus erythematosus: long-term outcome and predictors of mortality. Clin Rheumatol. 2017 Feb; 36(2):343-50.

15. Mackie FE, Kainer G, Adib N, Boros C, Elliott EJ, Fahy R, et al. The national incidence and clinical picture of SLE in children in Australia - a report from the Australian Paediatric Surveillance Unit. Lupus. 2015 Jan; 24(1):66-73.

16. Ramirez Gomez LA, Uribe OU, Uribe OO, Grisales Romero H, Cardiel MH, Wojdyla D, et al. Childhood systemic lupus erythematosus in Latin America. The GLADEL experience in 230 children. Lupus. 2008 Jun; 17(6):596-604.

17. Hiraki LT, Benseler SM, Tyrrell PN, Hebert D, Harvey E, Silverman ED. Clinical and laboratory characteristics and long-term outcome of pediatric systemic lupus erythematosus: a longitudinal study. J Pediatr. 2008 Apr; 152(4):550-6.

18. Hoffman IEA, Lauwerys BR, De Keyser F, Huizinga TWJ, Isenberg D, Cebecauer L, et al. Juvenile-onset systemic lupus erythematosus: different clinical and serological pattern than adult-onset systemic lupus erythematosus. Ann Rheum Dis. 2009 Mar; 68(3):412-5.

19. Agarwal I, Kumar TS, Ranjini K, Kirubakaran C, Danda D. Clinical features and outcome of Systemic Lupus Erythematosus. Indian Pediatr. 2009 Aug; 46(8):711-5.

20. Mina R, Brunner HI. Pediatric lupus: are there differences in presentation, genetics, response to therapy, and damage accrual compared with adult lupus? Rheum Dis Clin North Am. 2010 Feb; 36(1):53-80. 